\title{
Physical Education and Game Education in Preschool and Primary School
}

\section{Okul Öncesi ve Ilköğretimde Beden Eğitimi ve Oyun Eğitimi: Sistematik Derleme}

\author{
Alişan YAVUZ ${ }^{1}$ \\ (iD) https://orcid.org/0000-0003-0842-3123 \\ Institute of Education Sciences, Mehmet Akif Ersoy University, Burdur, Turkey

\section{Ebru ÖZÜDOĞRU} \\ (iD) https://orcid.org/0000-0002-6072-898X \\ Institute of Education Sciences, Mehmet Akif Ersoy University, Burdur, Turkey
}

\section{Fatma Çelik KAYAPINAR (iD) https://orcid.org/0000-0002-2159-1706 \\ Faculty of Sport Sciences, Izmir Demokrasi Üniversitesi, İmir, Turkey}

Received: September 3, 2019

Accepted: September 24, 2019

Online Published: September 30, 2019

DOI: 10.30655/besad.2019.22

https//:doi.org/10.30655/besad.2019.22

\begin{abstract}
The purpose of this study was to systematically analyze studies which were about game and physical education published between 2009-2019 years. Study was conducted through studies published on databases of Higher Education Institution (YOK) thesis dates between 2009-2019 years, Dergi park and Google Academic in terms of terms "physical education" and "game/play" in primary and secondary schools. There were 46 studies detected by physical education related three thesis from 548 master thesis, one doctoral dissertation; game related 30 thesis from 1661 master thesis, 12 doctoral dissertation. In dergi park database, 45 articles were selected; a) physical education related 13 articles from 28.160 articles, b) game/play related 32 articles from 1649 articles. In google academic database, 8 articles were determined; a) physical education related one article from 17100 articles, seven articles from 17.700 articles. There were 99 studies determined as 53 scientific researches, 33 master thesis and 13 doctoral dissertations in dates between 2009-2019. This study comprises of reviewing scientific researches in terms of physical education and game/play in preschool and primary school. Future directions have been discussed.
\end{abstract}

Keywords: Preschool, play, education, physical activity

${ }^{1}$ Corresponding author: Alişan YAVUZ

Mehmet Akif Ersoy Üniversitesi, Spor Bilimleri Fakültesi, Antalya Burdur Yolu, 15030, Yakaköy, Burdur, Turkey alisanyavuz32@gmail.com 


\section{Öz}

Çalışmamızda; okulöncesi ve ilköğretimde beden eğitimi ve oyun eğitimi ile ilgili 2009 ve 2019 yılları arasında yayınlanmış akademik çalışmaların gözden geçirilmesi ve çalışmalardan elde edilen verilerin sistematik biçimde incelenmesi amacıyla gerçekleștirilmiştir. Çalışma 2009-2019 yılları arasında Yüksek Öğretim Kurumu (YÖK) tez sorgu sayfasında yayınlanan doktora ve yüksek lisans tezleri ile Dergipark ve Google Akademi'de yayınlanan makaleler; okulöncesi ve ilköğretimde "beden eğitimi" ve "oyun" anahtar kelimelerinin kombinasyonu şeklinde literatür taraması yapılmıştır. YÖK tez sorgu sayfasında okulöncesi ve ilköğretimde; beden eğitimi ile ilgili 548 tezden Üç yüksek lisans tezi, bir doktora tezi, oyun ile ilgili 1661 tezden 30 yüksek lisans tezi, 12 doktora tezi olmak üzere toplam 46 çalışma tespit edilmiştir. Dergi Parkta okulöncesi ve ilköğretimde beden eğitimi ile ilgili 28160 bilimsel makaleden 13, oyun ile ilgili 1649 bilimsel makaleden 32 olmak üzere toplam 45 çalışma tespit edilmiştir. Google Akademikte ise okulöncesi ve ilköğretimde beden eğitimi ile ilgili 17.100 bilimsel makaleden bir, oyun ile ilgili 17.700 bilimsel makaleden 7 olmak üzere toplam 8 çalışma tespit edilmiştir. Okulöncesi ve ilköğretimde beden eğitimi ve oyun eğitimi ile ilgili 2009 ila 2019 yılları arasında yayınlanmış çalışmaların incelenmesi sonucu bu yıllar arasında 53 bilimsel makale, 33 yüksek lisans ve 13 doktora tezi olmak üzere toplam 99 bilimsel çalışma belirlenmiştir.

Anahtar Kelimeler: Okul öncesi, oyun, eğitim, fiziksel aktivite

\section{Giriş}

Okul öncesi dönemde bir çocuğun iletişiminin temel aracı hareketlerdir. Bir başka deyişle duygu ve isteklerini hareket yoluyla dile getirebilirler. Okulöncesi dönemde çocuk uzun süreli hareketlerde kuvvetini ya da pozisyonunu devam ettirebilecek güce sahip olmasa da denemelerle denge, ritim ve hareketlerde akıcılık yeteneğini geliştirebilmektedir. Okul öncesi eğitimde 36-72 aylık çocukların psikomotor, sosyal-duyusal, dil ve bilişsel gelişimlerinin desteklenmesini, öz bakım becerilerinin kazandırılması ve ilköğretime hazırbulunuşluklarının sağlanması amaçlanmaktadır (Topkaya \& Serbest, 2012, Şentürk, Yılmaz, \& Gönener, 2015).

Ilköğretimde sekiz yıl boyunca uygulanan beden eğitimi dersleri özellikle ilköğretimin 1. kademesinde oyunlar şeklinde uygulanmaktadır. Oyun kavramının temelinde de hareket becerilerinin kazanıması vardır. İnsan yaşamını daha sağlıklı ve nitelikli şekilde sürdürebilmek için hareket etmeye ihtiyaç duyar (Koç \& Tekin, 2011).

Okul dönemi çocuklarda, Beden Eğitimi ve Oyun dersi öğretim programı incelendiğinde; dersin ilkokul 1-4. sınıflarda okuyan öğrencilerin oyun oynama, fiziki etkinliklere katılma ve bu süreçlerde bedensel, zihinsel, kişisel, duygusal ve sosyal becerilerini gelişstirmelerine katkı sağlayacak tüm eğitim süreçlerini içerdiği görülmektedir. Bu eğitim süreçlerinde öğrencilerin yaş düzeyi, hazır bulunuşlukları, ilgileri, beklentileri, yöresel özellikler gibi etkenlerin dikkate alınması öngörüsü dile getirilmektedir. Dersin amacı göz önüne alındığında ise öğrencilerin oyun ve fiziki etkinlikler yolu ile yaşamları boyunca kullandıkları temel hareketler, aktif ve sağlıklı yaşam becerileri, kavramları ve stratejileri ile birlikte bunlarla ilişkili yaşam becerilerini geliştirerek bir sonraki eğitim düzeyine hazırlanmalarının sağlanması şeklinde ifade edilmektedir (Koç 2016). Bu amacın yanı sıra, bu dersin öğrencilerin hareket yetkinliği, aktif ve sağlıklı yaşam alışkanlıklarının altyapısının oluşturulması, Oyun ve fiziki etkinliklerde kendini tanıma, bireysel sorumluluk, kendine güven ve zaman yönetimi becerilerini, oyun ve fiziki etkinliklerde iletişim becerileri, işbirliği, adil oyun (fair play), sosyal sorumluluk, liderlik, doğaya duyarlıık ve farklııklara saygı özelliklerini geliştirir gibi muhtemel faydaları da beraberinde getireceği öngörülmektedir (MEB, 2018). 
Oyunlar, hayatımızın her döneminde var olan ve var olmaya devam edecek olan, her yaşta farklı amaçlar için kullanılan eğitici, geliştirici, eğlendirici yapılardır (Aksoy \& Yılmaz, 2011; Özyürek \& Çavuş, 2016). Oyun kavramını tanımlamak gerekirse, oyun Türk Dil Kurumu sözlüguünde, "yetenek ve zekâ geliştirici, belli kuralları olan, iyi vakit geçirmeye yarayan eğlence veya bedence ve kafaca yetenekleri geliştirmek amacıyla yapılan, çevikliğe dayanan her türlü yarışma" olarak tanımlanmaktadır (TDK, 2019).

TDK'nin bu tanımının yanı sıra literatürde oyun ile ilgili çok farklı tanımlar karşımıza çıkmaktadır. Dönmez (1992) oyunu, "belli bir amaca yönelik olan veya olmayan, kurallı ya da kuralsız gerçekleştirilen, fakat her durumda çocuğun isteyerek ve hoşlanarak yer aldığı, fiziksel, bilişsel, dilsel, duygusal ve sosyal gelişimin temeli olan, gerçek hayatın bir parçası ve çocuk için en etkin öğrenme süreci" olduğunu belirtir (s. 12-13). Cirhinlioğlu (2001)'da oyunu, "çocuğun gelişimi için en vazgeçilmez unsurlardan olup, çocuğun fiziksel, bilişsel, duyuşsal ve sosyal yönden gelişimini sağlayan önemli araçlardan" birisi olarak tanımlar (s. 167-168). Oyun, "eğlence amacının yanında nitelik ve nicelik açısından çocuğun gelişimini ve eğitimini tamamlayan ve de kültürel yapının sürekliliğini sağlayan bir faaliyettir" (Sümbüllü \& Altınışık, 2006). Yavuzer (2001) ise, "sonucu düşünülmeden, eğlenmek amacıyla yapılan hareket olarak oyunu tanımlamaktadır".

Oyun gibi insanlığın tüm kavşaklarında var olan fakat tek bir tanıma ulaşılamayan bir kavram için çeşitli oyun sınıflamalarının varlığı kaçınılmazdır. Bu bağlamda, oyun türlerine yönelik mevcut farklı sınıflamaları özetlemek gerekirse (Aytaş \& Uysal, 2017):

Elkind (2011)'e göre çocuklar, dört temel oyun türü yoluyla öğrenme yaşantılarını yaratırlar:

1. Ustalık oyunu, çocukların yeni kavramları ve becerileri kazanmalarını sağlar.

2. Yaratıcı oyun, çocuğun kavramları ve becerileri kazandıktan sonra çeşitlemeler üretmesiyle ortaya çıkar.

3. Yakınlık oyunu, çocuğun akran ilişkileri dünyasına kabulünü başlatır.

4. Terapötik oyun, çocuğa stresli yaşam olaylarıyla başa çıkabilmesi için stratejiler kazandırır.

Boratav (1973) ise oyunları şu şekilde sınıflamaktadır:

1. Sadece çocuklara özgü oyunlar

2. Talih, kumar, fal, niyet oyunları

3. Beceri ve güç oyunları

4. Zekâ oyunları

5. Katışımlı oyunlar).

Güneş (2003) ise oyunları aşağıdaki gibi gruplandıır:

1.Öğrenmeyi kolaylaştıran oyunlar

2.Sinıf ve salon oyunları

3.Bahçe oyunları

4. Topla oynanan oyunlar.

Bir başka değerlendirmeye göre oyunlar, şu şekilde sınıflandııııış (Moyles, 1992):

1.Fiziksel Oyun (Legolar, müzik enstrümanları, dans, tırmanma)

2.Entelektüel Oyun (Hikâye dinleme/anlatma, drama, sayı oyunları, boyama, tasarlama, çizme)

4.Sosyo, Duyusal Oyun (Kelime/sayı oyunları, rol alma oyunları).

Baran (1999) çocuk oyunlarını üç grupta değerlendirmiş ve aşağıdaki gibi tasnif etmiştir:

A. Gönlü hoş eden oyunlar: Gelişigüzel, taklit, donatım, tekerlemeli, türkülü, orta, falımsı ve vuruşmalı oyunlar. 
B. Usu geliştiren oyunlar: şaşırtmalı, bilmeceli, resimli, dilsiz ve ütümlü oyunlar.

C. Bedeni eğiten oyunlar: sportif ve avla ilgili oyunlar.

Bu çalışmada Baran'ın oyun gruplamasından "Bedeni Eğiten Oyunlar" grubundan "sportif oyunları", okul öncesi ve ilköğretim öğrencilerinde Beden Eğitimi ve Oyun kelimelerini ele alarak sistematik review olarak incelenmiştir. Tüm bilgiler ışığı altında okulöncesi ve ilköğretimde beden eğitimi ve oyun eğitimi ile ilgili 2009 ve 2019 yılları arasında yayınlanmış akademik çalışmaların gözden geçirilmesi ve çalışmalardan elde edilen verilerin sistematik biçimde incelenmesi amacıyla gerçekleştirilmiş olan derleme çalışması, yeni yapılacak olan akademik çalışmalara ışık tutması, araştırmacılara kaynak oluşturmak amacı ile çalışıımıştır.

\section{Yöntem}

Bu çalışmada 2009-2019 yılları dikkate alınarak literatür tarama yöntemi ile ulusal literatür incelenmiş ve Sistematik Review şeklinde düzenlenmiştir. Sistematik Review (derleme); klinik bir soruya yanıt ya da probleme çözüm oluşturmak için, o alanda yayınlanmış tüm çalışmaların kapsamlı bir biçimde taranarak, çeşitli dâhil etme ve dışlama kriterleri kullanarak ve araştırmaların kalitesi değerlendirilerek hangi çalışmaların derlemeye alınacağının belirlenmesi, derlemeye dâhil edilen araştırmalarda yer alan bulguların sentez edilmesidir (Burns \& Grove, 2007; Centre for Reviews and Dissemination [CRD], 2008; Higgins \& Green, 2011; Karaçam, 2013).

\section{Çalışma Evreni ve Örneklem}

Araştırma kapsamındaki çalışmalar, "Beden Eğitimi" ve "Oyun" ile ilgili nitel, nicel ve karma çalışmalardan oluşmaktadır. Çalışmada, hangi çalışmaların içerik analizine dâhil edileceğine yönelik seçimlerin yapılmasında aşağıdaki parametreler kullanılmıştır: Araştırmanın amacına yönelik 2009 ile 2019 yılları arasında "Oyun" ve "Beden Eğitimi" ile ilgili yayınlanmış çalışmalar analiz edilmiştir. Araştırmanın amacına yönelik ulusal ve Türkiye'de yapılmış uluslararası hakemli dergilerde yayımlanmış ulaşılabilen makaleler analiz edilmiştir. Araştırmanın amacına yönelik YÖK Ulusal Tez Merkezinden pdf uzantılı olarak erişilebilen yüksek lisans ve doktora tezleri analiz edilmiştir.

Araştırmanın amacına yönelik "Beden Eğitimi" ve "Oyun" anahtar kelimeleriyle ilgili yayınların içeriğinde egzersiz, spor ve enerji yakımıyla ilgili yayınlar çalışmamızın temelini oluşturmuştur (Baran, 1999; Çolak, 2015).

Çalışmada YÖK tez tarama sayfasından yüksek lisans ve doktora tezleri, Google Akademik arama motoru ve Dergipark'taki yayınlanan makaleler "Beden Eğitimi" ve "Oyun" anahtar kelimelerinin kombinasyonu şeklinde taranmıştır. Çalışmaların içerik analizine dahil edilme parametrelerine göre 53'ü makale, 33'ü yüksek lisans tezi, 13'ü doktora tezi olmak üzere toplamda 99 çalışmaya ulaşılmıştır.

\section{İçerik Analizi Yönergesi}

Araştırma kapsamında ulaşılan "Beden Eğitimi" ve "Oyun" ile ilgili toplam 99 çalışmanın analiz edilmesinde yedi soru kullanılmıştır. Bu sorulardan her biri araştırmada birer boyut olarak ele alınmıştır. İçerik analizi yönergesinde yer alan sorular aşağıdaki gibidir:

- Araştırma kapsamında incelenen çalışmaların, yayın türüne göre dağıımı nasıldır?

- Araştırma kapsamında incelenen çalışmaların, araştırma yöntemine göre dağılımı nasıldır?

- Araştırma kapsamında incelenen çalışmaların, yıllarına göre dağılımı nasııdır?

- Araştırma kapsamında incelenen çalışmaların, alanına göre dağılımı nasııdır? 
- Araştırma kapsamında incelenen çalışmaların araştırma alanının, araştırma türüne göre dağılımı nasıldır?

- Araştırma kapsamında incelenen çalışmaların araştırma alanının, araştırma yöntemine göre dağılımı nasıldır?

- Araştırma kapsamında incelenen çalışmaların araştırma yılının, araştırma türüne göre dağılımı nasıldır?

\section{Verilerin Analizi}

Her bir çalışma içerik analizi yönergesinde belirtilen yedi boyuta uygun olacak şekilde istatistik programında veriler kodlanıp, çalışmaların frekans (f) ve yüzde (\%) sonuçlarına ulaşılmışıı. Daha sonra çalışmanın her bir boyutu için elde edilen veriler tablolaştııımıştır.

\section{Bulgular}

Bu bölümde, araştırmanın amacına uygun olarak ulaşılan bulgular çalışmanın alt amaçlarına ilişkin başlıklar altında tablolaştırılarak sunulmuştur. Araştırma kapsamında incelenen çalışmaların, yayın türüne göre dağılımı Tablo 1'e göre, toplam 99 çalışmanın 53'ü makale türünde (\%53.5), 33'ü yüksek lisans düzeyinde (\%33,3) ve 13'ü doktora düzeyinde (\%13,1) gerçekleştirilmiştir.

Tablo 1. Çalışmaların yayın türüne göre dağııımı

\begin{tabular}{ccc}
\hline Yayın Türü & $\mathrm{F}$ & $\%$ \\
\hline Makale & 53 & 53,5 \\
Yüksek Lisans Tezi & 33 & 33,3 \\
Doktora Tezi & 13 & 13,1 \\
Toplam & 99 & 100,0 \\
\hline
\end{tabular}

Araştırma kapsamında incelenen çalışmaların, araştırma yöntemine göre incelenen toplam 99 çalışmaların 31'i nitel yöntem (\%31,3), 65'i nicel yöntemle (\%65,7), 3'ü karma araştırma yöntemiyle yürütülmüştür. Araştırma kapsamında incelenen çalışmaların, araştırma yılına göre dağılımı Tablo 2'ye göre, incelenen çalışmalarda en çok 2018 ve 2016 yıllarında çalışılmış olup, en az 2019 yılında çalışılmış olduğu anlaşılmaktadır.

Tablo 2. Çalışmaların araşstırma yılına göre dağılımı

\begin{tabular}{ccc}
\hline Araştırma Yilı & F & $\%$ \\
\hline 2009 & 4 & 4 \\
2010 & 3 & 3 \\
2011 & 8 & 3,0 \\
2012 & 9 & 9,1 \\
2013 & 3 & 3,0 \\
2014 & 8 & 8,1 \\
2015 & 9 & 9,1 \\
2016 & 18 & 18,2 \\
2017 & 16 & 16,2 \\
2018 & 20 & 20,2 \\
2019 & 1 & 1,0 \\
Toplam & 99 & 100,0 \\
\hline
\end{tabular}

Araştırma kapsamında incelenen çalışmaların, araştırma alanına göre dağılımı Tablo 3'e göre, incelenen çalışmaların 81'inin (\%81,8) "Oyun" alanında, 18'inin (\%18,2) "Beden Eğitimi" alanında yapılan çalışmalar olduğu belirlenmiştir. 
Tablo 3. Çalışmaların araştırma alanına göre dağıımı

\begin{tabular}{ccc}
\hline Araştırma Alanı & $\mathrm{F}$ & $\%$ \\
\hline Oyun & 81 & 81,8 \\
Beden Eğitimi & 18 & 18,2 \\
Toplam & 99 & 100,0 \\
\hline
\end{tabular}

Araştırma kapsamında incelenen çalışmaların araştırma alanının, araştırma türüne göre dağıımı Tablo 4'e bakıldığında, incelenen çalışmaların araştırma alanından biri olan "Oyunun" en çok araştırma türü makale olan çalışmalarda incelendiği belirlenmiştir.

Tablo 4. Çalışmaların araştırma alanının, araştırma türüne göre dağılımı

\begin{tabular}{ccccc}
\hline \multirow{2}{*}{ Araştırma Alanı } & \multicolumn{4}{c}{ Araşsırma Türü } \\
\cline { 3 - 5 } & Makale & $\begin{array}{c}\text { Yüksek Lisans } \\
\text { Tezi }\end{array}$ & Doktora Tezi & Toplam \\
\cline { 3 - 4 } & & 30 & 12 & 81 \\
Beden Eğitimi & 39 & 3 & 1 & 18 \\
Toplam & 14 & 33 & 13 & 99 \\
\hline
\end{tabular}

Araştırma kapsamında incelenen çalışmaların araştırma alanının, araştırma yöntemine göre dağılımı Tablo 5'i incelediğimizde, "Oyun" ve "Beden Eğitimi" alanında yapılan çalışmalarda en çok nicel araştırma yöntemi kullanımış, en az karma araştırma yöntemi çalışması kullanıldığı tespit edilmiştir.

Tablo 5. Çalışmaların araştırma alanının, araştırma yöntemine göre dağılımı

\begin{tabular}{ccccc}
\hline Araştırma Alanı & \multicolumn{4}{c}{ Araştırma Yöntemi } \\
\cline { 2 - 5 } & Nitel & Nicel & Karma & Toplam \\
\cline { 3 - 6 } Oyun & 29 & 49 & 3 & 81 \\
Beden Eğitimi & 2 & 16 & 0 & 18 \\
Toplam & 31 & 65 & 3 & 99 \\
\hline
\end{tabular}

Araştırma kapsamında incelenen çalışmaların araştırma yılının, araştırma türüne göre dağılımı Tablo 6'yı incelediğimizde, en az çalışma doktora tezi olarak yapılmış ve çalışmaya 2011 yılında başlanırken 2011 yıında hiç yüksek lisans tezi çalışması yapılmadığı tespit edilmiş olup, 2013 yılında da hiç makale yazılmadığı analiz edilmiştir.

Tablo 6. Çalışmaların araştırma yııının, araştırma türüne göre dağılımı

\begin{tabular}{|c|c|c|c|c|}
\hline \multirow[t]{2}{*}{ Araştırma Yılı } & \multicolumn{4}{|c|}{ Araştırma Türü } \\
\hline & Makale & $\begin{array}{c}\text { Yüksek Lisans } \\
\text { Tezi }\end{array}$ & Doktora Tezi & Toplam \\
\hline 2009 & 2 & 2 & 0 & 4 \\
\hline 2010 & 2 & 1 & 0 & 3 \\
\hline 2011 & 6 & 0 & 2 & 8 \\
\hline 2012 & 4 & 2 & 3 & 9 \\
\hline 2013 & 0 & 3 & 0 & 3 \\
\hline 2014 & 6 & 2 & 0 & 8 \\
\hline 2015 & 5 & 2 & 2 & 9 \\
\hline 2016 & 8 & 6 & 4 & 18 \\
\hline 2017 & 9 & 5 & 2 & 16 \\
\hline 2018 & 10 & 10 & 0 & 20 \\
\hline 2019 & 1 & 0 & 0 & 1 \\
\hline Toplam & 53 & 33 & 13 & 99 \\
\hline
\end{tabular}




\section{Tartışma ve Sonuç}

Okulöncesi ve ilköğretimde beden eğitimi ve oyun eğitimi ile ilgili 2009 ila 2019 yılları arasında yayınlanmış çalışmaların incelenmesi sonucu bu yıllar arasında 53 bilimsel makale, 33 yüksek lisans ve 13 doktora tezi olmak üzere toplam 99 bilimsel çalışma belirlenmişsir. İncelenen bu çalışmalarda oyun ve hareketin çocukların sosyal gelişimlerinin yanı sıra fiziksel, zihinsel ve motor gelişimleri açısından çok önemli olduğu sonucuna ulaşmak mümkün. Bu bağlamda okul öncesi ve ilköğretimden başlayarak çocukların düzenli ve bilinçli olarak hareket etmeleri sağlanmalıdır. Bunun da en iyi yollarından birinin oyun olduğu, oyunun çocuklar için olduğu ve insanın bir gelişim evresi olan çocukluk döneminin destekleyicisi olarak ele almak gerektiğini göz ardı etmemek gerekir.

Ceylan ve Dalaman (2017) yaptıkları bir araştırmada evreni temsil eden örneklem grubunun, büyük bir bölümü oyun ve fiziki etkinlikler dersinin çocuğun sağlığının gelişmesi için önemli olduğu görüşünü savunduğunu belirtmişlerdir. Yine aynı çalışmada öğretmenlerin, oyun ve fiziki etkinlikler dersinin çocuğun çok yönlü gelişimine büyük oranda katkıda bulunduğu görüşünde olduklarını ortaya koymuşlardır.Durualp ve Aral ise (2018) çocukların ince ve kaba motor gelişimlerine oyun etkinliklerinin etkisinin incelenmesi üzerine yaptıkları bir çalışmada oyun etkinliklerinin çocukların ince motor ve toplam motor gelişimlerini arttırdığını belirlemişlerdir.

Günümüzde başta teknolojik gelişmeler (telefon, tablet, bilgisayar oyunları) olmak üzere pek çok faktöre bağlı olarak çocukların giderek daha hareketsiz bir yaşam tarzı benimsedikleri görülmektedir. Özellikle oyun çağındaki çocuklar zamanlarının çoğunu teknolojik aletlerinin başında oturarak geçirmektedirler ve hareketsiz yaşam tarzı çocukluktan başlayarak alışkanlık haline gelmektedir. Yukarıda da bahsettiğimiz üzere, çocukluk çağından itibaren kazanılan egzersiz ve hareket alışkanlığının ilerleyen yaşlarda da sağlığı önemli ölçüde etkilediği bilinmektedir. Çocukluktan itibaren daha hareketli bir yaşam tarzı benimseyen bireyler bunu ilerleyen yaşlarda da devam ettirmekte ve yaşıtlarına göre kronik hastalıklara yakalanma intimalleri düşük olmaktadır (Taşkın \& Şahin Özdemir, 2018).

Gelecekteki yaşam tarzının daha sağlıklı ve uzun olabilmesi için çocukluk döneminden itibaren daha hareketli bir yaşam tarzı benimsenmesi önemlidir. Düzenli hareket ve fiziksel aktivite alışkanlığı okul öncesi dönemde kazandırımalıdır; zira okul öncesi dönemdeki çocukların hareket etmesini sağlamak ergenlik dönemindeki çocuklara göre çok daha kolaydır. Çünkü temel hareketler dönemindeki (2-6 yaş) çocuklarda hareket, öğrenme ve iletişim kurmanın vazgeçilmez unsurudur ve hızlı gelişim süreci içinde yeni motor becerileri öğrenmeye hazır durumdadırlar (Gallahue \& Donnely, 2003).

Sonuç olarak; okul öncesi ve ilkokul döneminde spor ve fiziksel aktiviteleri artırılmalı ve çocuklar küçük yaştan itibaren bu konuda spor bilimciler ve uzmanlar tarafından bilinçlendirilmelidir. Uygulamaların yapıldığı kapalı ve açık alanlar düzenlenmelidir. Hareket eğitiminin uygulanabilmesi için gerekli araç-gereç ve ortam sağlanmalıdır. Hareket eğitimi programlarının süreleri artırılarak çocukların gelişim düzeyleri gözlemlenmeli, ilkokul ve 5-6 yaş grubundaki okul öncesi eğitim kurumlarında Beden Eğitimi dersinin zorunlu olarak verilmeli ve derslere alandan eğitimciler girmeli. Gelişmiş ülkelerde olduğu gibi okulöncesi dönemden başlayarak hareket ve sporun tüm toplumda düzenli bir alışkanlık haline getirilmesinin devlet politikası olması gerektiği düşünülmektedir. Okul öncesi ve ilkokul dönemindeki çocukların fiziksel gelişimleri açısından yaş grubunun özelliklerine uygun, düzenli ve planlı, uzmanlar denetiminde uygulanan aktivitelere katılmaları, değişik oyunlar ve eğlendirici ekipmanlarla sporun sevdirilmesi önem arz etmektedir. 


\section{Kaynakça}

Aytaş, G., \& Uysal, B. (2017). Oyun Kavramı ve Sınıflandırılmasına Yönelik Bir Değerlendirme. Celal Bayar University Journal of Social Sciences. 15 (1), 675-690.

Baran, M. (1999). Çocuk Oyunları. Ankara: Kültür Bakanlığı Yayınları.

Boratav, P. N. (1973). 100 Soruda Türk Folkloru. İstanbul: Bilgesi Yayıncılık.

Burns, N., \& Grove, S. K. (2010). Understanding nursing research-eBook: Building an evidence-based practice. Elsevier Health Sciences.

Ceylan, G. C., \& Dalaman, O. (2017). Illkokul II. sınıf oyun ve fiziki etkinlikler dersi kazanımlarının gerçekleşme düzeyine ilişkin öğretmen görüşleri. Uluslararası Eğitim Bilimleri Dergisi. (10) 235-254.

Cirhinlioğlu, F. G. (2001). Çocuk ruh sağlığı ve gelişimi. Ankara: Nobel yayıncılık.

Çolak, M. (2015). Adana Geleneksel Çocuk Oyunları. Niğde Üniversitesi Sosyal Bilimler Enstitüsü Türk Dili ve Edebiyatı Anabilim Dalı, Yayımlanmamış Yüksek Lisans Tezi. Niğde.

Dönmez, N. B. (1992). Oyun kitabı. İstanbul: Esin yayınevi.

Durualp, E., \& Aral, N. (2018). Çocukların ince ve kaba motor gelişimlerine oyun etkinliklerinin etkisinin incelenmesi. Afyon Kocatepe Üniversitesi Sosyal Bilimler Dergisi. 20 (1) 243-258.

Elkind, D. (2011). Oyunu gücü. Ankara: Imge Yayınları.

Gallahue, D. L., \& Donnely, F. C., (2007). Developmental Physical Education for All Children. Champaign: Human Kinetics.

Güneş, H. (2003). Çocuk oyunları. Ankara: Anı Yayıncılık.

Karaçam, Z. (2013). Sistematik Derleme Metodolojisi: Sistematik Derleme Hazırlamak Için Bir Rehber. Dokuz Eylül Üniversitesi Hemşirelik Fakültesi Elektronik Dergisi. 6 (1) 26-33.

Koç, H., \& Tekin, A. (2011). Beden eğitimi derslerinin çocuklarda seçilmiş motorik özellikler üzerine etkisi. Yüzüncü Yıl Üniversitesi Eğitim Fakültesi Dergisi. 8 (Özel).

Koç, E. S. (2015). Oyun ve Fiziki Etkinlikler Dersi Öğretim Programının Karşılaştırmalı Olarak Incelenmesi (Kanada Örneği). Kastamonu Eğitim Dergisi. 24(1) 263-280.

MEB. (2018). Oyun ve fiziki etkinlikler dersi öğretim programı (1-4. sınıflar). Ankara: Devlet kitapları müdürlüğü basımevi.

Moyles, J. R. (1992). Just playing. Philadelphia: Open University Press.

Özyürek, A., \& Çavuş, Z. S. (2016). İlkokul öğretmenlerinin oyunu öğretim yöntemi olarak kullanma durumlarının incelenmesi. Kastamonu Eğitim Dergisi 24 (5) 2157-2166.

Sümbüllü, Y. Z., \& Altınışık, M. E. (2016). Geleneksel Çocuk Oyunlarının Değerler Eğitimi Açısından Önemi. Erzurum Teknik Üniversitesi Sosyal Bilimler Enstitüsü Dergisi. 1 (2) 73-85.

Şentürk, U., Yılmaz, A., \& Gönener, U. (2015). Okul Öncesi Dönemde Motor Gelişime Yönelik Hareket Eğitimi ve Oyun Çalışmalarının İçerik Analizi. Spor Yönetimi ve Bilgi Teknolojileri. 10 (2).

Taşkın, G., \& Şahin Özdemir, F. N. Ş. (2018). Çocuklarda Egzersizin Önemi. Gazi Beden Eğitimi ve Spor Bilimleri Dergisi. 23 (2) 131-141. 
TDK. (2019, 05). TDK:

http://www.tdk.gov.tr/index.php?option=com_gts\&arama=gts\&guid=TDK.GTS.5ce52eabcoe56 0.70996507 adresinden alındı

Topkaya, I.., \& Serbest, Ş. (2012). Okul Öncesi Eğitimde "Oyun ve Hareket Etkinlikleri" Öncesinde Psikomotor Alan Eğitimi. Ankara: Nobel Akademik Yayıncılık.

Yavuzer, H. (2001). Çocuk Psikolojisi. İstanbul: Remzi Kitabevi.

Yılmaz, G. K., Aksoy, N. C. (2011). Kesirler Konusunda Uygulanan Oyun Destekli Öğretimin Altıncı Sınıf Öğrencilerinin Matematiğe Yönelik Tutumlarına Etkisi. Bayburt Eğitim Fakültesi Dergisi. 6 (1) 105-117. 